\title{
Microstructural Changes of 22Cr-9Mo-3Fe-4Nb Ni-Base Superalloy during Creep
}

\author{
Youngseok Song ${ }^{1}$, Jinik Suk ${ }^{1}$, and Chung-Yun Kang ${ }^{2, *}$ \\ ${ }^{1}$ Materials Development Team, Doosan Heavy Industries \& Construction, Changwon 51711, Republic of Korea \\ ${ }^{2}$ Department of Materials Engineering, Pusan National University, Busan 46287, Republic of Korea
}

\begin{abstract}
A new Ni based superalloy is considered as bucket material because of high fatigue resistance with fine grain. However a bucket is usually exposed to high temperature for a long time, so creep rupture tests were conducted to understand the microstructure evolution during creep deformation under various stresses at temperatures of 566, 593, 621, 649 and $670{ }^{\circ} \mathrm{C}$. The hardness applied to the crept specimen of these alloys increased until the value of LMP reached 25, and decreased while the value of LMP exceeded 25. The microstructure analysis with TEM, SEM and OM were conducted on ruptured specimen to observe the changes of $\gamma^{\prime \prime}$ morphology, carbides, and fracture mode. As a result of investigating microstructural changes and creep properties, it can be concluded that the effect of grain size on creep properties is dominant regardless of the size of $\gamma^{\prime \prime}$.
\end{abstract}

(Received December 5, 2016; Accepted January 14, 2017)

Keywords: alloys, forging, creep, microstructure, TEM

\section{INTRODUCTION}

In recent years, the maximum steam temperature in turbine of fossil power plant has been raised in order to improve thermal efficiency. In conventional steam turbines, ferritic heat-resistant steels have been widely used as bucket materials until now. However, in ultra-super critical and hyper super critical, Ni based superalloys are considered as bucket materials according to system design requirements because of high creep property, fatigue and corrosion resistant. The system of candidate material is $22 \mathrm{Cr}-9 \mathrm{Mo}-$ $3 \mathrm{Fe}-4 \mathrm{Nb} \mathrm{Ni}$ base alloy. These candidate alloy have a solid solution hardened FCC structure, which is strengthened by chromium, molybdenum, iron, niobium, and so on. BCT structured and ordered in an intermetallic compound type phase, with a disc shaped gamma double $\operatorname{prime}\left(\gamma^{\prime \prime}\right)$, is the principal strengthening phase in this alloy [1].

The alloy containing carbides are $\mathrm{MC}$ and $\mathrm{M}_{6} \mathrm{C}$ (rich in nickel, niobium, molybdenum and carbon). In addition, $\mathrm{M}_{23} \mathrm{C}_{6}$, a chromium-rich carbide, appears in solution-treated material exposed at temperatures lower than $566{ }^{\circ} \mathrm{C}$. This

*Corresponding Author: Chung-Yun Kang [Tel: +82-51-510-2428, E-mail: kangcy@pusan.ac.kr] Copyright (c) The Korean Institute of Metals and Materials phase gradually transforms to orthorhombic $\mathrm{Ni}_{3} \mathrm{Nb}$ when the alloy is heated for long time in the temperature range of 566 to $670{ }^{\circ} \mathrm{C}$ because of the high niobium content. Niobium, a body centered cubic (BCC) Group VA element, is one of the major refractory elements used in superalloys along with molybdenum, tungsten and tantalum. These alloying elements added singly or in combination, contribute to solid solution strengthening, and precipitation hardening as well. Niobium has lower modulus, melting point and density than the other refractory elements [2-3]. The alloy shows high strength and toughness over a wide temperature range besides excellent fatigue strength, oxidation, and corrosion resistance. Bucket material needs fine grain for good fatigue properties, and it is also important to understand the effect of stress, temperature, and time on creep properties in the operation condition. Several investigations were carried out to understand the microstructural change at operation condition by previous studies. However, there were not much works related to long term creep test at intermediate temperature with fine grain material.

Based on this reason, creep rupture tests were conducted with various stresses at intermediate temperature. The microstructure analysis such as TEM, SEM and OM were 
Table 1. Chemical composition of alloy D1 and D2 [wt\%], Al/Ti ratio $\approx 1$

\begin{tabular}{ccccccccc}
\hline El. & $\mathrm{Cr}$ & $\mathrm{Mo}$ & $\mathrm{Nb}$ & $\mathrm{C}$ & $\mathrm{Si}$ & $\mathrm{Al}+\mathrm{Ti}$ & $\mathrm{Fe}$ & $\mathrm{Ni}$ \\
\hline D1\&D2* & 22.2 & 8.7 & 3.6 & 0.02 & 0.17 & 0.39 & 2.9 & Bal. \\
\hline
\end{tabular}

*D1 \& D2: different forging condition

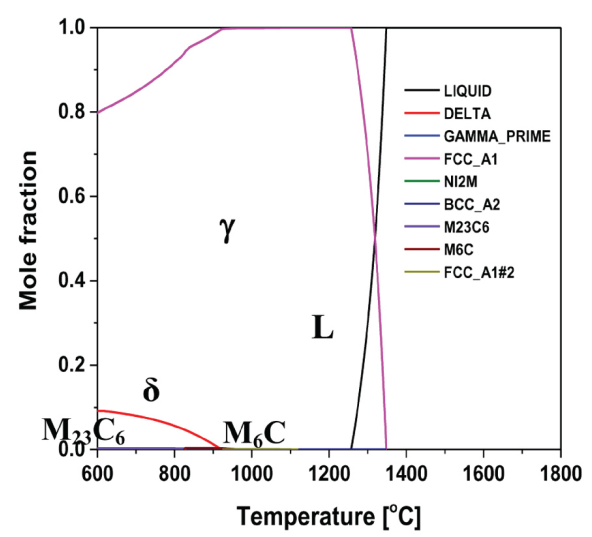

Fig. 1. The calculated phase diagram of $22 \mathrm{Cr}-9 \mathrm{Mo}-3 \mathrm{Fe}-4 \mathrm{Nb} \mathrm{Ni}$ base alloy by Thermo-calc

conducted on ruptured specimen to observe the change of $\gamma^{\prime \prime}$ morphology, detrimental phases and carbides transformation behavior. The degradation mechanism was suggested and used to determine optimum alloy which was predicted by diagram calculated by thermo-calc as shown in Fig. 1.

\section{EXPERIMENTAL PROCEDURE}

The chemical composition of the alloy Ni-22Cr-9Mo-3Fe$4 \mathrm{Nb}$ is given in Table 1. Chemical composition was analysed by optical emission spectroscopy (Spectro Lab LAVM11) Forged round bar with a diameter of $100 \mathrm{~mm}$ was prepared by double melting process (VIM-ESR) and open die forging. Creep rupture tests were carried out on annealed material to understand creep behaviours and the microstructure evolution during creep with various stresses at 566, 593, 621, 649 and $670{ }^{\circ} \mathrm{C}$. Gauge and fractured areas of creep tested samples were analysed for the microstructural characterization by field emission scanning electron microscopy (JP-JSM5200).

The samples were electrolytically etched using chromic acid to reveal the carbides and intermetallic phases. The microstructure analysis by transmission electron microscopy (JP-JEM2100F) was also conducted on ruptured specimen to

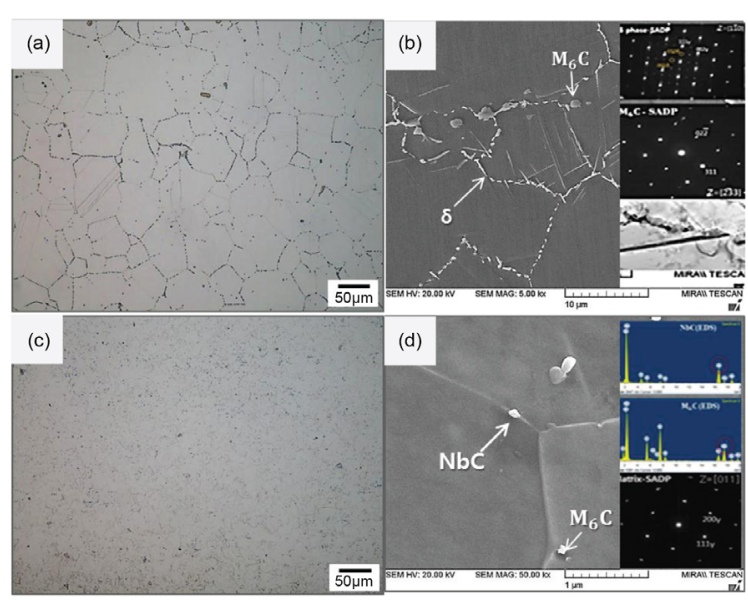

Fig. 2. The initial microstructure of alloys before test; (a) and (b) for D1 alloy, (c) and (d) for D2 alloy

observe the change of $\gamma^{\prime \prime}$ morphology and transformation. Hardness was also measured by Mitutoyo HM-122 with 300 gf of Load.

\section{RESULTS AND DISCUSSION}

\subsection{Initial microstructure before test}

Figure 2 shows the microstructure of alloys which are annealed at $920{ }^{\circ} \mathrm{C}$ for $2 \mathrm{hrs}$ and quenched by water.

The D1 alloy has uniform grain distribution of 15 20 micrometer. There were precipitation bands with delta $(\delta)$-Phase and $\mathrm{M}_{6} \mathrm{C}$ carbides at grain boundary and matrix partially.

The D2 alloy has fine grain of about 10 micrometer. It has Niobium carbides in $100 \mathrm{~nm}$ and $\mathrm{M}_{6} \mathrm{C}$ type carbides at grain boundary and matrix. $\delta$-Phase was not observed.

\subsection{Creep properties}

The creep rupture results obtained at various temperatures and stress levels in the present study are plotted in the form of Larson-Miller Parameter (LMP) in Fig. 3. A value of 25 was used as the Larson-Miller constant [4-6]. The LMP linearly increased with decrease in stress. LMP $\left[=\mathrm{T}(25+\log \operatorname{tr}) \times 10^{-3}\right]$ is a function of both temperature and time, hence, the combination of these parameters controls the evolution of the microstructure of creep specimens. Figure 3 shows the effect of the temperature changes between $566{ }^{\circ} \mathrm{C}$ and $670{ }^{\circ} \mathrm{C}$ on 


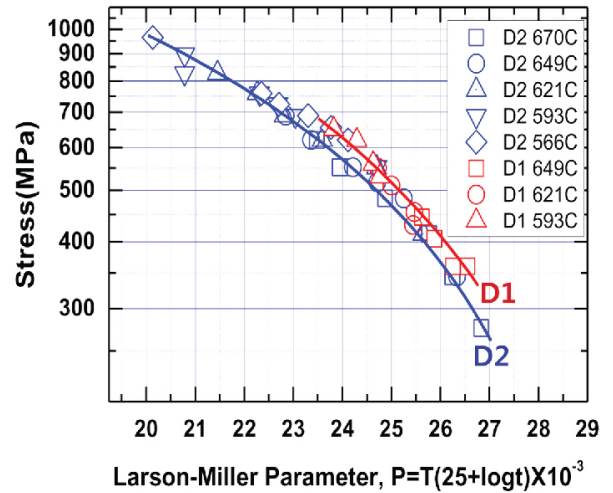

Fig. 3. The results of creep rupture strength in terms of Larson miller parameter of D1 and D2 alloy

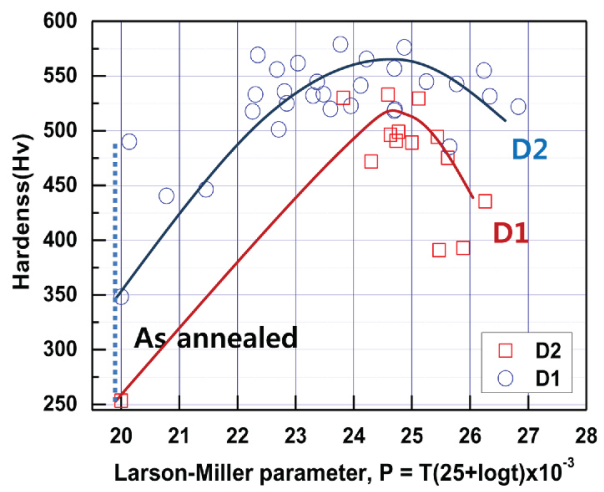

Fig. 4. Results of hardness behavior for creep ruptured specimen according to Larson miller parameter changes

the creep rupture strength of alloys. The stress is plotted against LMP in terms of alloys and the tested temperature.

It is evident that the creep rupture time depends on both temperature and stress. The creep strength of alloy D1 is higher than that of alloy D2.

The hardness of these alloys increased until the value of LMP increased up to 25, and decreased with LMP increase above 25 (Fig. 4).

It is related with the microstructural changes such as coarsening of precipitate and phase transformation.

\subsection{Microstructure evolution of alloys during creep}

The coarsening of $\gamma^{\prime \prime}$ precipitates in candidate alloys during creep test was observed. The mechanism for coarsening is analyzed in terms of the interaction between applied stress and temperature. Figure 5 shows the evolution of microstructure
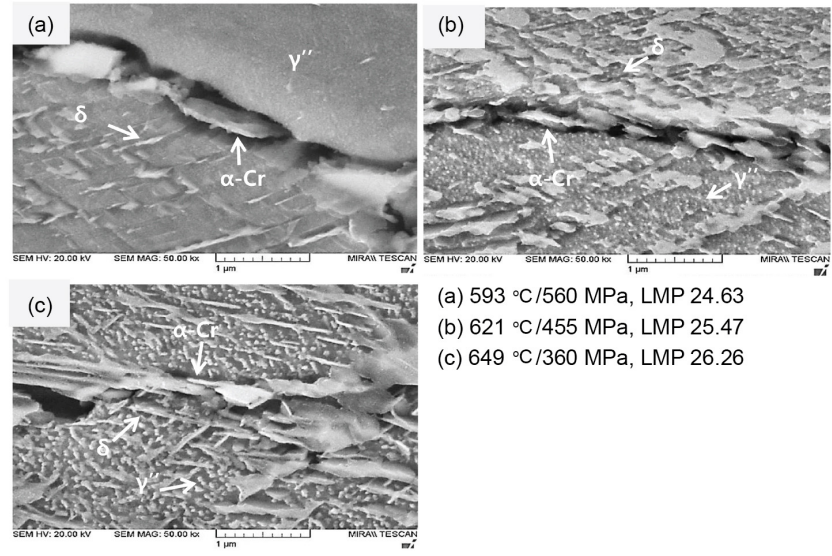

(a) $593^{\circ} \mathrm{C} / 560 \mathrm{MPa}$, LMP 24.63

(b) $621^{\circ} \mathrm{C} / 455 \mathrm{MPa}$, LMP 25.47

(c) $649^{\circ} \mathrm{C} / 360 \mathrm{MPa}$, LMP 26.26

Fig. 5. The evolution of microstructure during creep in alloy D1
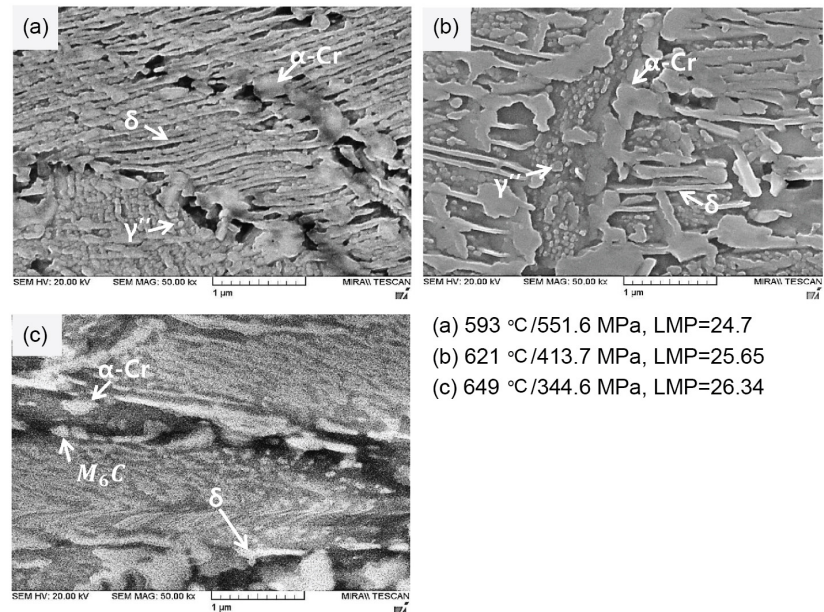

(a) $593^{\circ} \mathrm{C} / 551.6 \mathrm{MPa}, \mathrm{LMP}=24.7$

(b) $621^{\circ} \mathrm{C} / 413.7 \mathrm{MPa}, \mathrm{LMP}=25.65$

(c) $649{ }^{\circ} \mathrm{C} / 344.6 \mathrm{MPa}, \mathrm{LMP}=26.34$

Fig. 6. SEM micrographs show changes of microstructure as LMP increased at various temperatures in alloy D2

during creep in alloy D1. SEM micrographs showing the grain boundary as the LMP increased with various temperatures in alloy D1. $\gamma^{\prime \prime}$ is finely precipitated in the matrix with the size of about $11.5 \mathrm{~nm}$. $\delta$-Phases were formed across the grain and $\alpha$ - $\mathrm{Cr}$ (Chromium enriched bcc phase) was randomly precipitated along the grain boundary(Fig. 5a)

Figure $5 \mathrm{~b}$ ) shows that $\gamma^{\prime \prime}$ is finely precipitated in the matrix, the size of $\gamma^{\prime \prime}$ is about $24.55 \mathrm{~nm}$. It also shows $\delta$ phase formed continuously while $\alpha-\mathrm{Cr}$ is also discontinuously precipitated on grain boundary.

Figure $5 \mathrm{c}$ ) shows that $\gamma^{\prime \prime}$ is precipitated coarsely in the matrix with size of about $48.5 \mathrm{~nm}$ and $\delta$-Phases are formed coarsely. $\alpha$-Cr is precipitated on grain boundary continuously.

In case of alloy $\mathrm{D} 2, \gamma^{\prime \prime}$ is precipitated coarsely in the matrix 


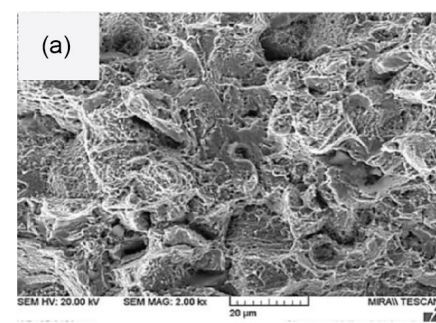

(b)

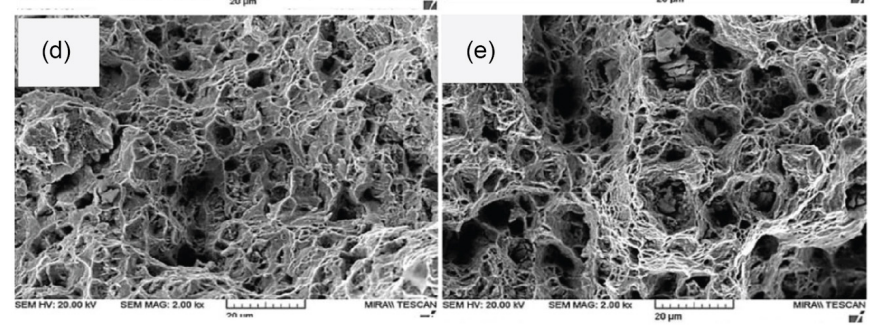

(c)
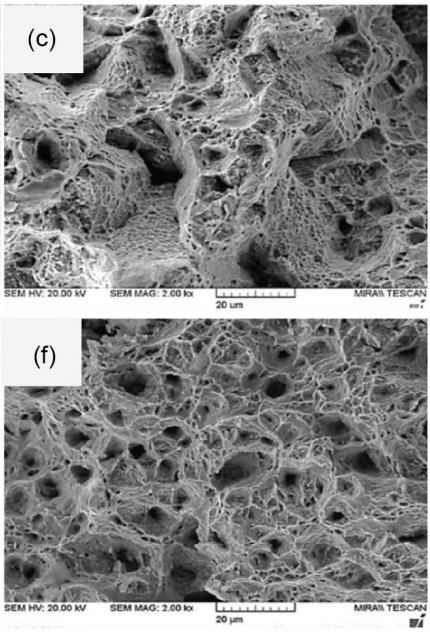

Fig. 7. Fractography of the creep ruptured specimen at various creep conditions in alloy D1 \& D2 (a), (b) and (c) for alloy D1, (d), (e) and (f) for alloy D2. a) LMP $24.63,593{ }^{\circ} \mathrm{C} / 560 \mathrm{MPa}$ b) LMP $25.47,621{ }^{\circ} \mathrm{C} / 455 \mathrm{MPa}$ c) LMP $26.26,649{ }^{\circ} \mathrm{C} / 360 \mathrm{MPa}$, d) LMP $24.7,593$ ${ }^{\circ} \mathrm{C} / 551.6 \mathrm{MPa}$ e) LMP $25.65621{ }^{\circ} \mathrm{C} / 413.7 \mathrm{MPa}$ f) LMP $26.34,649{ }^{\circ} \mathrm{C} / 344.75 \mathrm{MPa}$

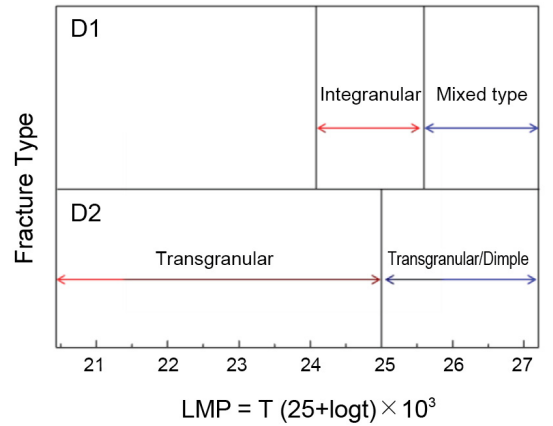

Fig. 8. The changes of fracture mode as LMP increased

with size of about $21 \mathrm{~nm}, \delta$-Phase are formed across the grain and $\alpha-\mathrm{Cr}$ is precipitated on grain boundary discontinuously as shown in Fig. 6 a).

Figure $6 \mathrm{~b}$ ) shows that the size of $\gamma^{\prime \prime}$ is about $46.7 \mathrm{~nm}, \delta$ -Phases are formed and $\alpha$-Cr is precipitated on grain boundary sporadically. However, $\gamma^{\prime \prime}$ is not observed in matrix and grain boundary, instead fine $\delta$-phases are observed discontinuously in matrix. $\mathrm{M}_{6} \mathrm{C}$ and $\alpha-\mathrm{Cr}$ are also precipitated in the matrix in Fig. $6 \mathrm{c})$.

Figure 7 shows the changes of fracture mode during creep according to LMP and stress. It show that intergranular fracture mode is dominant at low LMP and the dimple mode increase at higher LMP in D1 alloy (Fig. 7 a) $\sim$ c)).

In case of D2 alloy (Fig. 7d) f)), It shows that the transgranular fracture mode is dominant to the value of LMP
25. However, the fracture mode become transgranular with deep dimples on the fracture surface with LMP 26.34 in Fig. 7. The change of fracture modes during creep is summarized in Fig. 8.

Transformation phase has been identified by SEM and TEM with SAD analyses. Fig. 9 a) show that $\delta$-phases were detected and distributed across the matrix, it also reveals $\gamma^{\prime \prime}$ exists without $\delta$ phase within the matrix. The size of $\gamma^{\prime \prime}$ was up to $11.5 \mathrm{~nm}$. $\gamma^{\prime \prime}$ can be expected to be degenerate into $\delta$ -phase by the following reaction [7]

$$
\gamma^{\prime \prime}(\mathrm{Ni3}[\mathrm{Nb}, \mathrm{Al}, \mathrm{Ti}]) \rightarrow \delta(\mathrm{Ni3} \mathrm{Nb})+\gamma^{\prime}(\mathrm{Ni} 3[\mathrm{Al}, \mathrm{Ti}])
$$

$\alpha-\mathrm{Cr}$, chromium enriched bcc phase is precipitated between grain boundary and delta phase in D1 alloy. It is reported that $\alpha$-Cr formation is related to $\mathrm{Cr}$ in $\mathrm{Ni}$ based superalloys when $\mathrm{Cr}$ content is higher than $16 \mathrm{wt} \%$ according to $\mathrm{B}$. Lindsley reported [8].

$\alpha$-Cr forms along the $\delta$-phase where the $\mathrm{Cr}$ and Fe levels are the highest in the matrix, due to the rejection of these elements from the $\delta$-phase and relatively slow diffusion of these elements in the matrix at test temperatures [8].

Figure $9 \mathrm{~b} \sim \mathrm{c}$ ) show $\alpha$-Cr is precipitated with $\delta$-phase at grain boundary and $\gamma^{\prime \prime}(24.5 \mathrm{~nm}$ to $48.5 \mathrm{~nm})$ coarsening in the matrix with increasing the value of LMP. The case of alloy 


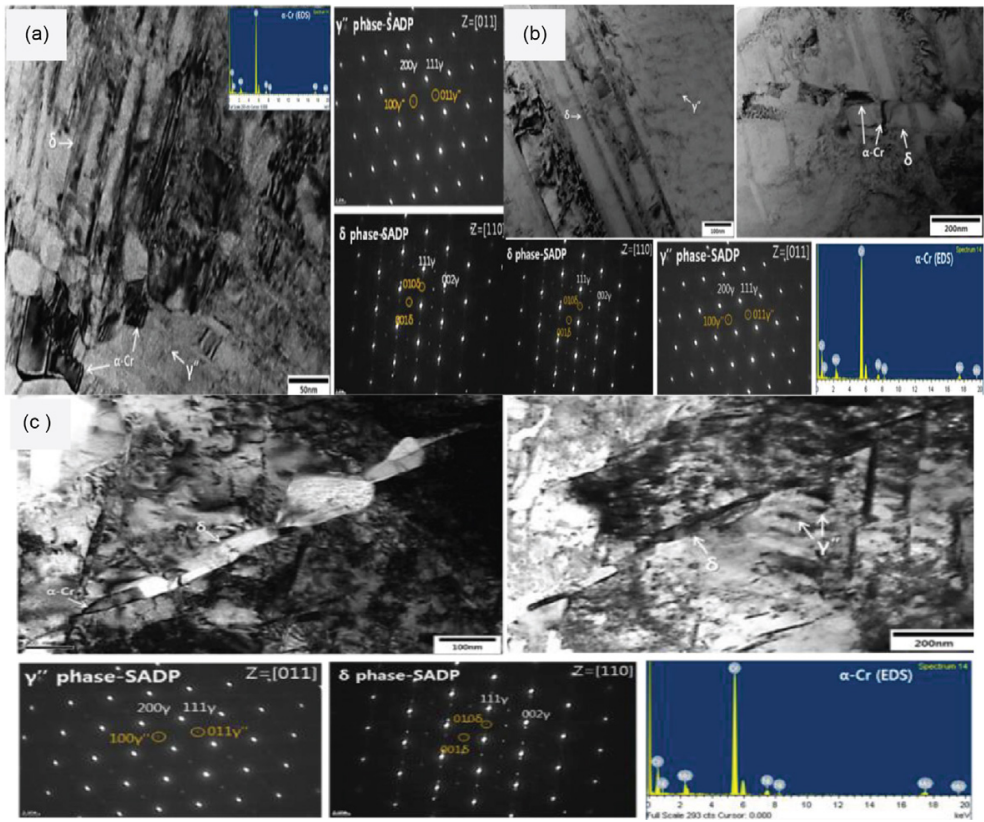

Fig. 9. TEM micrograph of alloy D1

a) LMP $24.63,593{ }^{\circ} \mathrm{C} / 560 \mathrm{MPa}$ ) $\operatorname{LMP} 25.47,621{ }^{\circ} \mathrm{C} / 455 \mathrm{MPa}$ c) LMP $26.26,649{ }^{\circ} \mathrm{C} / 360 \mathrm{MPa}$

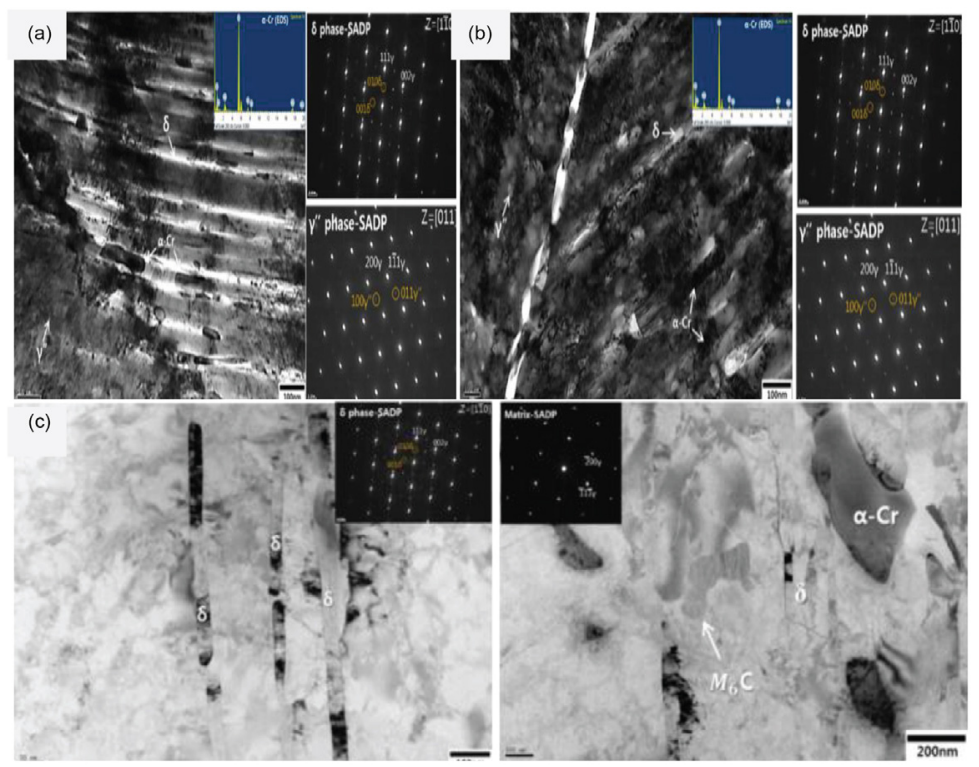

Fig. 10. TEM micrograph of alloy D2

LMP 24.7,593 ${ }^{\circ} \mathrm{C} / 551.6 \mathrm{MPa}$ ) LMP $\left.25.65,621{ }^{\circ} \mathrm{C} / 413.7 \mathrm{MPa}, \mathrm{c}\right) \mathrm{LMP} 26.34,649{ }^{\circ} \mathrm{C} / 344.75 \mathrm{MPa}$

D2 in Fig. 10 shows a similar behavior of microstructure with alloy D1 in a view of $\delta$-phase, $\gamma^{\prime \prime}$ coarsening and $\alpha-\mathrm{Cr}$ precipitation. The size of $\gamma^{\prime \prime}$ is changed from $21 \mathrm{~nm}$ to 46.7 $\mathrm{nm}$ until the value of LMP reached 25.65. However, it was shown that $\alpha$-Cr dominantly forms at the vicinity of $\delta$-phase and the grain boundaries are continuously decorated with $\delta$ -phase without $\gamma^{\prime \prime}$ in the matrix as increased to the value of LMP 26.34 at $649{ }^{\circ} \mathrm{C}$ with $344.75 \mathrm{MPa}$. Besides, $\gamma^{\prime}$ was not detected as well.

As a result of microstructural investigation, $\alpha-\mathrm{Cr}$ is detected as increasing the value of LMP.

During the subsequent creep, the MC type carbide 


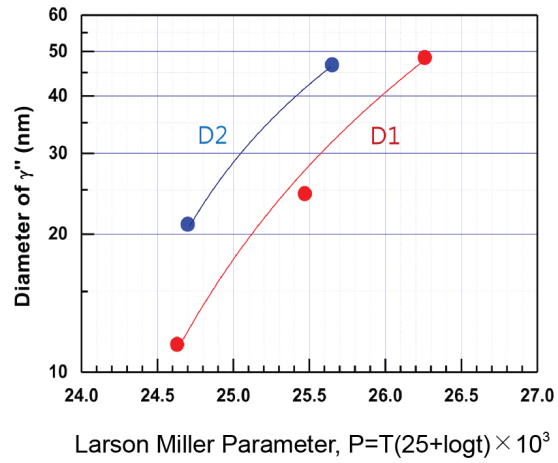

Fig. 11. The Comparison of $\gamma^{\prime \prime}$ size between alloy D1 and D2 by measured

generally degenerates into chromium-containing $\mathrm{M}_{23} \mathrm{C}_{6}$ type carbide by the following reaction $[1,7,8]$.

$$
\mathrm{MC}+\gamma=\mathrm{M}_{23} \mathrm{C}_{6}+\gamma^{\prime}
$$

On the other hand, in this alloy system, there were no $\mathrm{M}_{23} \mathrm{C}_{6}$. Only $\mathrm{M}_{6} \mathrm{C}$ was detected. Low level carbon content around $0.02 \mathrm{wt} \%$ is believed to be the reason for these candidate alloys. $\mathrm{MC}$ carbides dominantly contain $\mathrm{Nb}$ content and Niobium is known to retard the reaction of MC type carbides to $\mathrm{M}_{23} \mathrm{C}_{6}$ type carbides [8].

These TEM images show that the size of $\gamma^{\prime \prime}$ of alloy D2 is coarser than that of alloy D1 as the value of LMP increased from 24.5 to 26.5 as shown in Fig. 11.

\section{CONCLUSIONS}

A polycrystalline Ni-based superalloy was studied with respect to its microstructural evolution during creep with various stresses at $566,593,621,649$ and $670{ }^{\circ} \mathrm{C}$ by SEM and TEM.
The hardness is increased as the value of LMP increased to about 25 and then decreased.

As the LMP is increased, the size of $\gamma^{\prime \prime}$ gradually increased up to $48.5 \mathrm{~nm}$ and it was transformed to $\delta$-Phase and coarsened in both alloy D1 and D2. TEM observations showed that discontinuous $\alpha$-Cr on grain boundary.

It can be concluded that the effect of grain size is dominant on creep properties during intermediate temperatures regardless of the size of $\gamma^{\prime \prime}$ due to the total amount of $\gamma^{\prime \prime}$ is small.

\section{ACKNOWLEDGEMENT}

This work was supported by the Technology Innovation Program (No.10052860) funded by the Ministry of Trade, industry \& Energy, Republic of Korea.

\section{REFERNECES}

1. S. J. Patel and G. D. Smith, Superalloys 718, 625, 706 and Derivatives, TMS, 135 (2005).

2. M. Sundararaman, P. Mukhopadhyay and S. Banerjee, Metall. Trans. A 19A, 453 (1988).

3. Ming Gao, Shuchun Chen, D. Gary Harlow, and Robert P. Wei, Metall. Mater. Trans. A 27A, 3391(1996).

4. Alonso Peralta-Duran and Paul H. Wirsching, CreepRupture Reliability Analysis, NASA CR 3790, 12 (1984).

5. Gandy and J. Shingledecker, Advances in Materials Technology for Fossil Power Plants, ASM International, 1347 (2014).

6. Special Metals Corporation, Inconel alloy718, Http://www.specialmetals.com/ assets/documents/alloys/ inconel/inconel-alloy-718.pdf, 19 (2016).

7. S. T. Wlodek and R. D.Field, Superalloys 718,625 and Various Derivatives, TMS, 659 (1994).

8. B. Lindsley, X. Pierron, and G. Maurer, The Long Term Stability of High Temperature Materials, TMS, 123 (1999). 